\title{
Bones of contention
}

$\mathrm{B}$ ones, mummified corpses and other human remains have long been part of museum exhibitions. They are meant to provide insight into cultural practices, scientific developments or historic events, not feed voyeuristic curiosity. But what about using human remains in an art exhibition for political or esthetic purposes? Is that different? Should that be taboo?

Such questions confronted the cityfinanced Ottawa Art Gallery as it prepared for the Oct. 1 opening of "Witness," by nichola feldman-kiss, an established artist known for her explorations into identity, the body and colonialism.

"Witness" is billed as a mid-career retrospective with works in various media from video to sculpture. One installation, "Between Here and There," includes an imported human skeleton purchased online by the artist from the British Columbia medical supply company Osta International.

The Ottawa Art Gallery says the skeleton installation aims to "memorialize the existence of the anonymous individual whose remains slipped through the interstices of international law to become the legitimate offering of the western medical market." The artist's point: contemporary bodies, like yesterday's slaves, can be bought and sold across international boundaries.

So, what are the skeleton's origins?

Initially, Osta would only tell feldman-kiss the skeleton was Asian. Further research by the artist and the gallery pointed to Taiwan and that the skeleton is actually composed of bones from multiple people. Even if these people had donated their bodies to science, it is unlikely they consented to spend their afterlives as part of an art exhibition. That lack of consent raises ethical red flags in the usually anything-goes art world.

North American ethnocultural museums, such as the Canadian Museum of History, tend to exhibit human remains only with the consent of the appropriate cultural community. Thus, the museum obtained consent from the Greek government for the current exhibition on ancient Greece that included human bones.

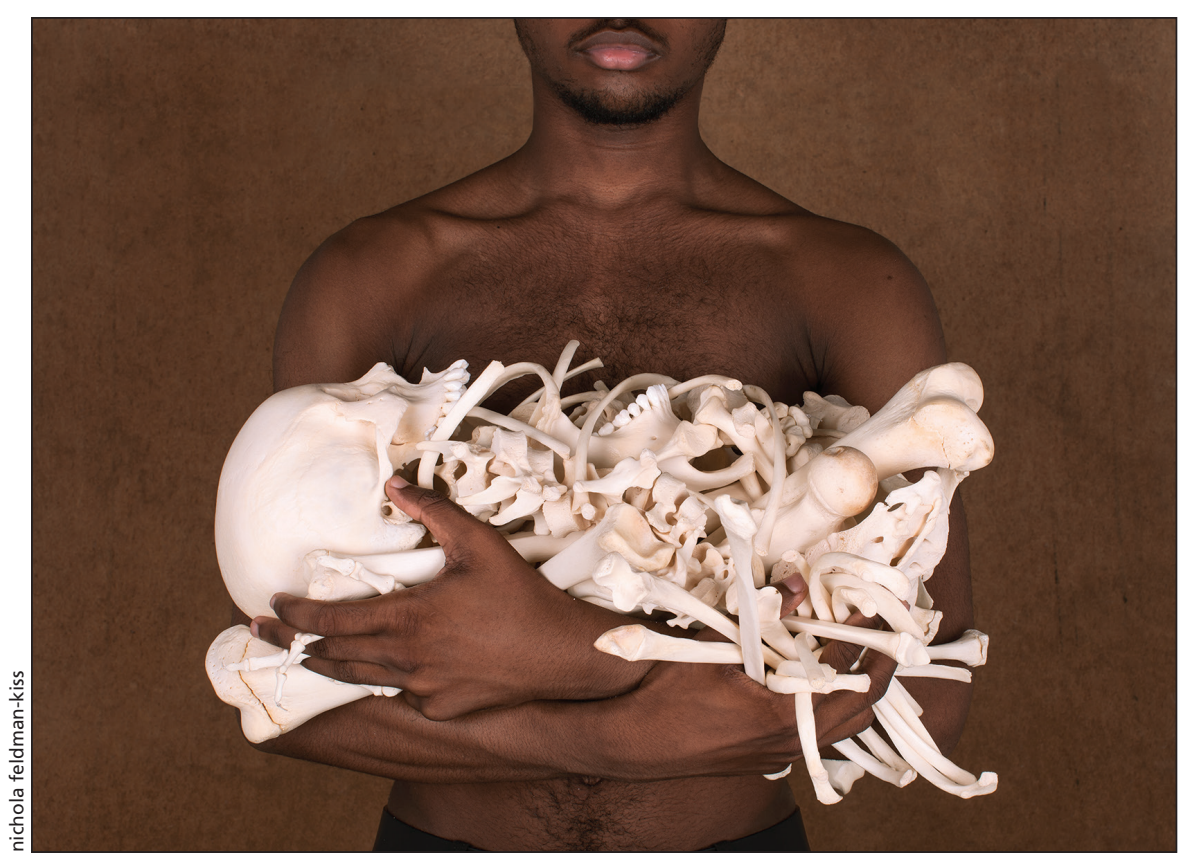

The art photo "Between Here and There" depicts an imported human skeleton purchased online by the artist.

Somewhat nervously, the Ottawa Art Gallery consulted a lawyer, its own board of directors and a medical ethicist before opening "Witness." Dr. Jeff Blackmer, vice-president of medical professionalism for the Canadian Medical Association, was among those consulted. "I don't have a fundamental concern with this as long as people attending are made aware of the context and the potential controversies," says Blackmer. The gallery planned to provide such context, as well as a warning for visitors that a human skeleton is present.

But some art curators and academics took a dimmer view when consulted before the opening of the exhibit.

Gatineau-based Stephan St-Laurent has a reputation as a daring art curator. While heading Ottawa's SAW Gallery, St-Laurent curated an exhibition about human excrement; another exhibition involved a performance artist deliberately wounding himself and spraying his HIV-positive blood onto his surroundings. But St-Laurent says "digging up human bodies and putting them on public display - there is almost something sacrilegious about that."

Diana Nemiroff, the former contemporary art curator at the National Gallery of Canada, was likewise unsettled.
"Personally, I would prefer that human remains be left out of artworks; there are so many artificial alternatives. But I realize that [the artist's] intent may be to raise the moral issue, which leaves us with a dilemma."

Stephen Inglis is a former director of research and collections for the Canadian Museum of History. He notes that television shows like "CSI" feed into a growing popular interest in forensics. But, simultaneously, people are increasingly squeamish about exhibiting human remains. "It's a little bit ironic — going in two different directions at once."

A dichotomy of views also surrounds the globe-trotting exhibitions of plastinated corpses called "Body Worlds." Some people find the exhibitions educational. Others say the use of corpses is exploitative. And there are questions about whether these bodies were donated or obtained in nefarious ways.

The origins of feldman-kiss' skeleton are also murky; feldman-kiss does not pretend to have all the answers. "My goal is for people to leave with a set of questions about the way they live and what kind of world we live in and want to live in." - Paul Gessell, Ottawa, Ont.

CMAJ 2015. DOI:10.1503/cmaj.109-5164 